\title{
Raising a child with down's syndrome: perspectives from South African urban care-givers.
}

\author{
Megan D. Barr, Pragashnie Govender, Gina Rencken
}

University of KwaZulu-Natal (Westville Campus), South Africa

\begin{abstract}
Objectives: This study addresses a gap from a South African urban perspective on the knowledge and emotional responses of caregivers with children diagnosed with Down's syndrome (DS). The study is an initial step towards informing health professionals who adopt a biopsychosocial approach, in an effort to improve interventions for both caregivers and children.

Methods: A simple descriptive survey was utilized with 57 participants who were caregivers of children with DS. Data was analyzed descriptively using the Statistical Package for Social Scientists (SPSS) (version 21).

Results: The caregivers' initial reactions when discovering that the child had DS included shock, sadness and anxiety. When considering the etiology of Down's syndrome, findings reflected that caregivers understood DS as a medical condition relating to chromosomal abnormalities rather than attribution of the syndrome to a fault of their own. Despite the immediate reactions, the caregivers' initial emotions toward the child rather than the situation were positive and unchanged by the subsequent challenges in caring for the child. The caregivers indicated feelings of love toward the child notwithstanding the diagnosis.

Conclusion: This study allowed for the subjective experience, perceptions and attitudes of caregivers to be investigated, and raised further questions into the deeper meanings and experiences of caregivers towards assisting practitioners in understanding the dynamics surrounding care-giving that may influence holistic interventions.
\end{abstract}

Keywords: Down's syndrome, caregivers, perceptions, emotional responses.

DOI: http://dx.doi.org/10.4314/ahs.v16i4.7

Cite as: Barr MD, Govender P, Rencken G. Raising a child with downn's syndrome: perspectives from South African urban caregivers. Afri Health Sci 2016;16(4): 929-935. http://dx.doi.org/10.4314/abs.v16i4.7

\section{Introduction}

A review of the available literature revealed limited relevant evidence related to raising a child with Down's syndrome (DS) within an African context. ${ }^{1}$ Although many aspects such as physical characteristics ${ }^{2,3}$ and health difficulties ${ }^{3}$ have been identified and found to be similar in individuals with DS, many aspects of the syndrome are not yet comprehensively understood particularly when it comes to the dynamics of interpersonal relationships

\author{
Correspondence author: \\ Pragashnie Govender, \\ Discipline of Occupational Therapy \\ School of Health Sciences \\ University of KwaZulu-Natal \\ (Westville Campus) \\ Private Bag X54001 \\ Durban, 4000 \\ Tel: +27 312608258 \\ Mobile: +27716056931 \\ E-mail: naidoopg@ukzn.ac.za
}

between the child with DS and the coping mechanisms used by those with whom the child lives. The purpose of this study was to thus explore the dynamics surrounding raising a child with DS from the caregivers perspective.

With increasing research in and around children with DS globally, there is the hope that a greater understanding of the syndrome will assist towards adequately incorporating these children into society; ${ }^{4}$ decrease the cases of neglect, ${ }^{5}$ ensure that rehabilitative intervention is optimized to enhance quality of life for both the person with DS and their caregivers, and help to increase successful experiences of both the child with DS and their caregivers. Providing additional research within an African context may contribute to enhancing practitioner's interventions related to care-giver support.

\section{Literature review}

There exists a vast amount of research internationally on DS, emanating primarily from the United States of America and United Kingdom. ${ }^{6-12}$ The development of the diagnosis, now commonly known as Down's syn- 
drome, is one that transformed from the original derogatory term 'Mongolian Idiocy' in 1961. ${ }^{13}$ The official term 'Down syndrome' was later acknowledged by the World Health Organisation (WHO) in 1965. ${ }^{13}$ In South Africa, the prevalence of DS is not widely researched, ${ }^{14}$ yet it has been found that approximately 1 in every 600 children is born with DS, reflecting a high incidence rate. ${ }^{15}$ This is comparable to the United States, where approximately 1 in every $800-1,000$ children is born with DS. ${ }^{12}$

Despite the constitutional rights of South Africans, children are still discriminated against within the South African context and this is often related to a lack of understanding of their condition or disability. ${ }^{5}$ This insufficiency in knowledge extends to what is then required of caregivers when raising a child with the syndrome, both emotionally and in terms of material resources.

According to the theory proposed by Elisabeth KüblerRoss, ${ }^{16}$ parents that have children with congenital disorders such as DS will more often than not undergo an emotional reaction when discovering the child's diagnosis. This subjective feeling is said to somewhat resemble that of bereavement as the parents are mourning the loss of that 'normal' child. ${ }^{16,17}$ There is the need to come to terms with major life changes which requires adapting to novel circumstances and experiences. ${ }^{8}$ Moreover during the stage of 'acceptance' according to the theory, the individual or caregiver in this instance has not necessarily come to terms with what has happened. Instead this stage highlights the acceptance of the reality of the situation and that it cannot be changed. ${ }^{8,9,18}$

Within the African and to an extent South African context there is an air of prejudice and judgment when considering children that are not 'normal' or typically developing. ${ }^{5,19}$ Culture is a large factor governing the reactions and attitudes of individuals within Africa, whereby rural men have been found to leave their family due to the stigmatization and perceptions that their community has towards the child, ${ }^{5}$ often attributing the occurrence to curses, religious misdoings and failure of the parents. ${ }^{5}$ As a result, these children are often kept hidden away from the judging public and raised in a single-parent household. ${ }^{5}$ Additionally, most of the attention of the parent/s and/ or caregiver/s is often directed toward the child with 'spe- cial needs' as they require more support and often at the expense of other children which may result in animosity, resentment and additional family issues ${ }^{6}$.

From a psychodynamic perspective, it is essential to explore the factors that aid or challenge caregivers in raising a child with DS. This may ultimately aid health care practitioners when dealing with caregivers of DS through providing culturally relevant interventions which may reduce the adverse emotional and coping effects of raising a child with the syndrome.

\section{Methods}

A descriptive survey was utilized in this study. Participants included any individual who predominantly cares for a child with DS, including parents. 57 participants via purposive sampling were recruited from listings from the Down's syndrome KwaZulu-Natal data base and outreach programmes. The descriptive survey was electronically forwarded to the Down's syndrome Association KwaZulu-Natal members together with their newsletter.

The following criteria was utilized when selecting participants

i. Members of the Down's syndrome Association KwaZulu-Natal.

ii. Individuals that attend the genetic clinics that the Down's syndrome Association KwaZulu-Natal includes in their outreach programme;

iii. Individuals that attend the hospitals that the Down syndrome Association KwaZulu-Natal includes in their outreach programme;

iv. The child that the caregivers care for had to have a formal diagnosis of Down's syndrome;

v. All participants needed to reside within KwaZulu-Natal;

vi. All participants needed to communicate in either English or isiZulu as their home language or be bilingual in these languages

The survey was divided into five sections that addressed areas of the participants' experiences. The first section involved biographical data which allowed for participant profiling and acquisition of prevalence factors (such as age, gender, type of Down's syndrome). The other sections involved attitudes of the participant, community 
and family; challenges and coping; experiences of caring for the child and emotional experiences. The last section allowed for participants to select more than one answer which enhanced their ability to express themselves.

The survey was distributed to five caregivers of children with Down's syndrome selected from the Down syndrome Association KwaZulu-Natal data base. The feedback resulted in identification of ambiguous questions as well as difficulties that could be experienced due to double negatives, especially for first language isiZulu speakers. The information assisted in adjusting the questions so that they were easier to understand and the descriptive survey was more comprehensible. The adjusted surveys were sent back to the original five participants who did not report any further difficulties. A statistician was consulted for data analysis with use of the Statistical Package for Social Scientists (SPSS), version 21. The authors upheld ethical principles of confidentiality, informed consent and justice throughout the research process.

\section{Results}

\section{Demographics}

Of the 57 participants, majority, that is $71.9 \%$ were female. A total of $47.4 \%$ were of African descent, $40.4 \%$

Caucasian, 7\% Coloured and 5.3\% were of the Indian race. The participants were predominantly English speakers $(54.4 \%)$. The child gender percentages comprised $49.1 \%$ male and $50.9 \%$ female. A number of participants $(38.6 \%)$ cared for a child under the age of five years followed by $26.3 \%$ caring for children between the ages of five to ten years. The remaining participants (35.1\%) cared for children older than ten years. A large percentage $(89.5 \%)$ of the children were diagnosed with Trisomy 21 whilst $7 \%$ percent of the participants indicated that they were unaware of the type of DS. Of the sample, $94.7 \%$ of the participants indicated that they were the biological parent with $1.8 \%$ being a guardian or family member. In terms of living circumstances, $52.6 \%$ of the participants lived in a city or town, $28.1 \%$ lived in townships $15.8 \%$ lived in informal settlements and 3.5\% were living in other settings.

\section{Initial emotional responses}

Caregivers were requested to choose as many options that were applicable (represented in both Figures 1 and 2). In Figure 1 it can be seen that caregivers generally felt anxiety $(34.8 \%)$ once they discovered that the child had a diagnosis of Down's syndrome followed by being upset $(18.8 \%)$ and having mixed feelings (15.9\%). (Add Figure 1)

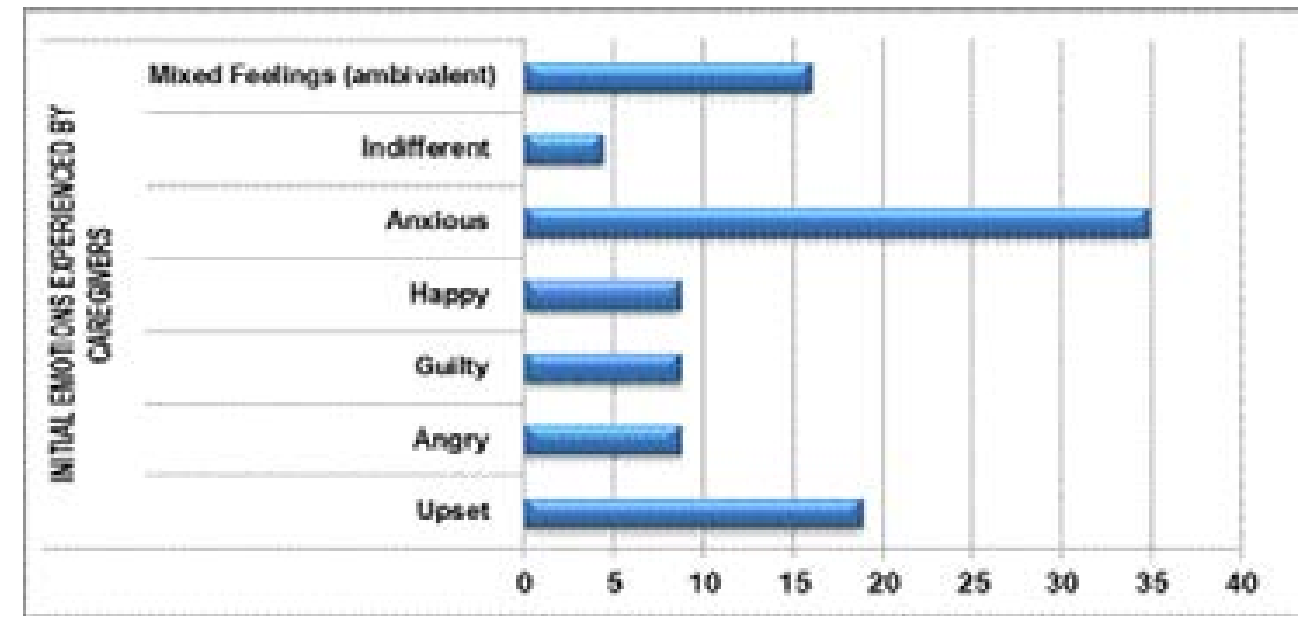

Figure 1: Initial emotions experienced by caregivers to the diagnosis of $D S(n=69)$

Although initial reactions were not entirely positive, Figure 2 shows that the most significant emotion experienced by the caregivers to the child was love $(31.9 \%)$, followed by confusion (23.6\%), anxiety $(16.7 \%)$ and disappointment (12.5\%). Emotions of happiness (6.9\%), mixed feelings $(6.9 \%)$ and indifference $(1.4 \%)$ reflected lower scores. ( Figure 2) 


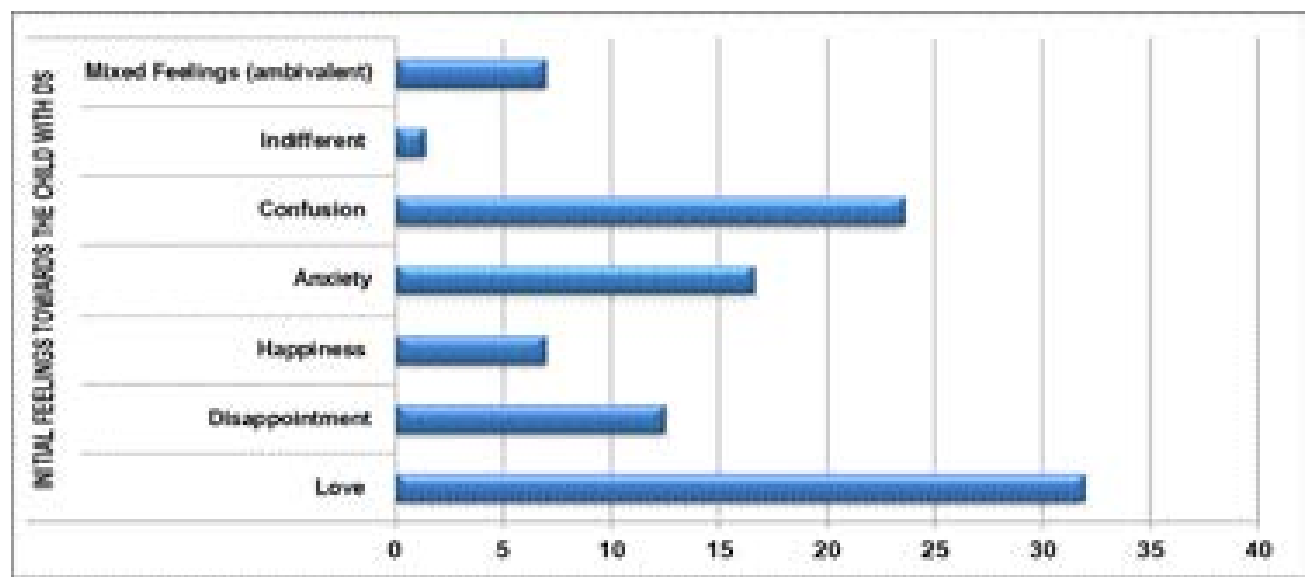

Figure 2: Initial feelings toward the child with DS $(n=72)$

Level of Knowledge and Understanding of DS

Caregivers were requested to indicate one choice (represented in Figures 3 and 4) as to their knowledge of DS. Of the 59 responses received, the majority of caregiv- ers $(50.8 \%)$ had limited knowledge and understanding of DS initially, followed by $32.2 \%$ having basic knowledge, $13.6 \%$ having no knowledge and 3.4\% having good knowledge of the condition. (Figure 3)

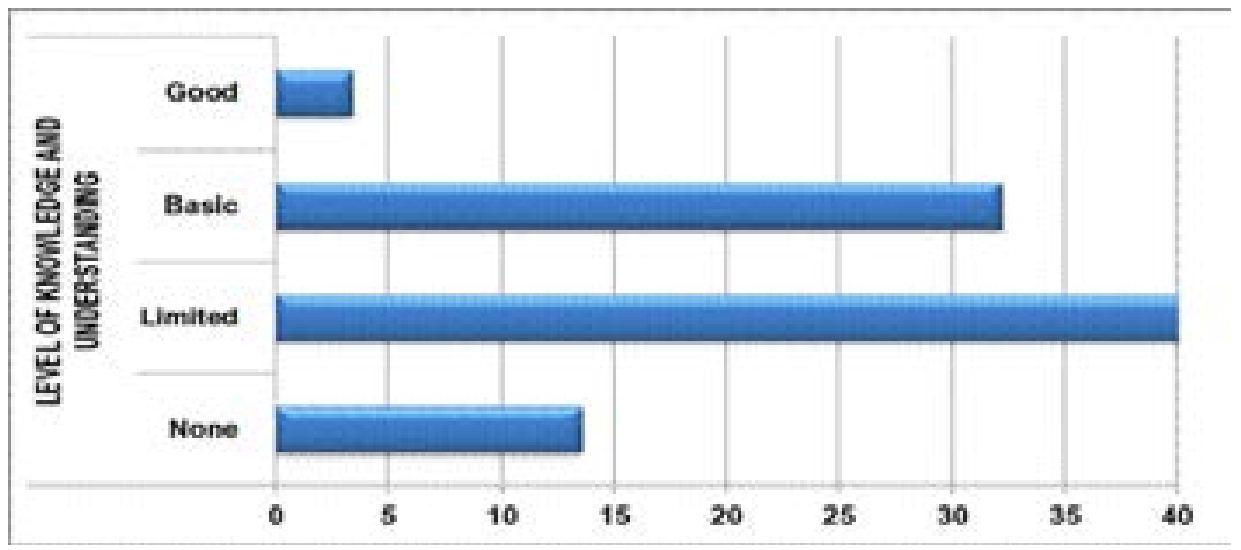

Figure 3: Initial level of knowledge/understanding of DS $(n=59)$

Although knowledge of DS was limited (Figure 3), majority $(70.2 \%)$ knew that it is a medical condition with
$3.5 \%$ indicating that it was caused through a fault of their own. A number of the caregivers $(26.3 \%)$ reported that they did not know the cause (Figure 4)

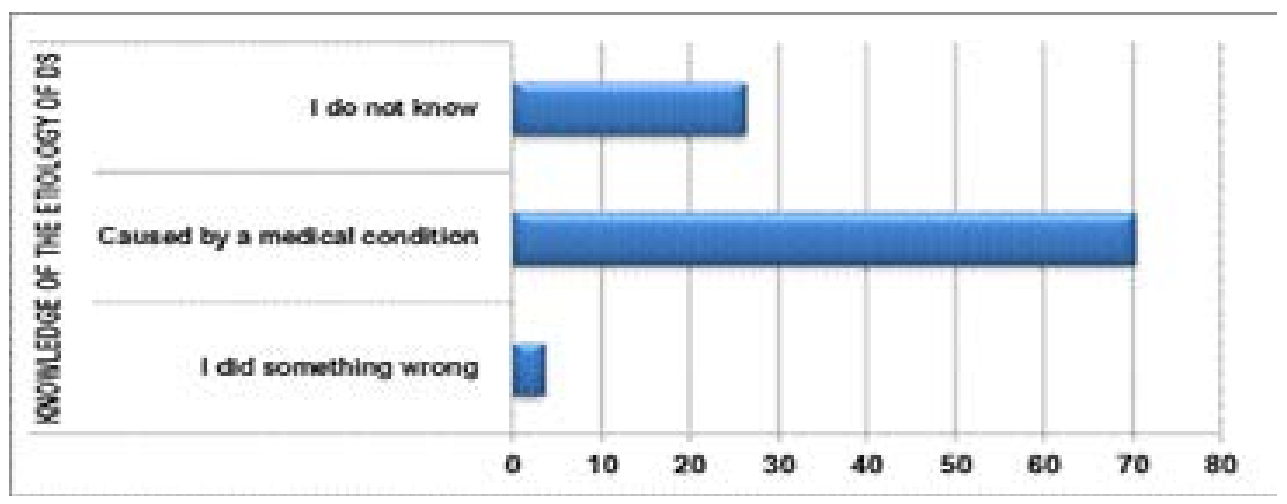

Figure 4: Participants' knowledge of the etiology of DS $(n=57)$ 
Reactions of family and communities from the caregiver's perspective.

Caregivers were requested to choose as many options that were applicable when considering their emotions when disclosing the child's status to their communities and fami- ly members (Figure 5). Caregivers primarily demonstrated mixed emotions (being ambivalent) towards disclosure to the family $(37.9 \%)$ and the community $(30.3 \%)$, followed by indifference from family $(19.7 \%)$ and the community $(30.3 \%)$. ( Figure 5)

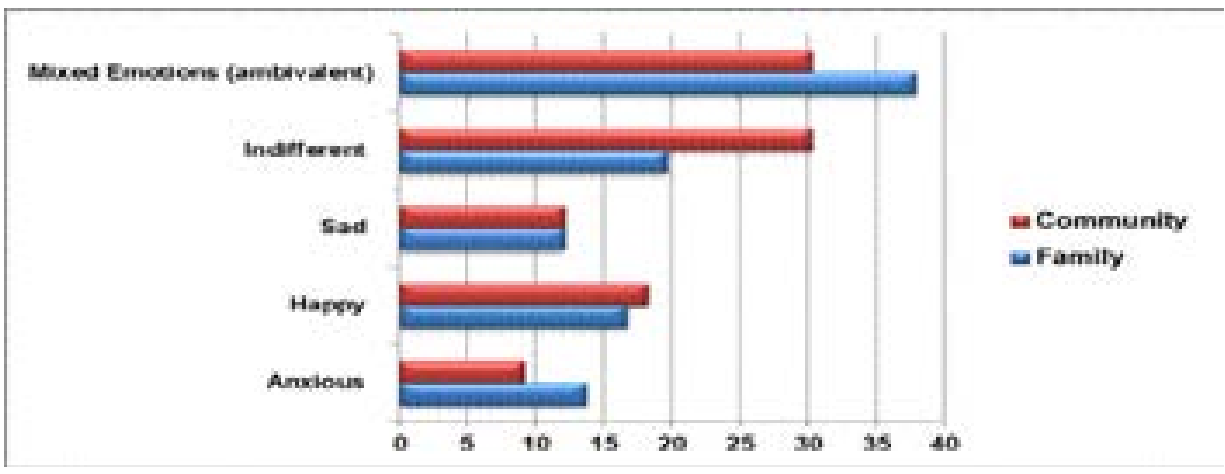

Figure 5: Emotions experienced during disclosure to family and community $(n=66)$

\section{Emotions experienced in raising the child with DS}

Majority of caregivers experienced a sense of happiness $(70 \%)$ in caring for the child with DS. A percentage of caregivers also admitted to having $(26.2 \%)$ mixed feelings. Hopelessness $(1.8 \%)$ and a level of fatigue $(1.8 \%)$ were less frequently indicated.

\section{Resources available to caregivers}

Figure 6 represents the resources to which caregivers had access to. Caregivers were able to choose more than one option to show the array or lack of access to resources. Most caregivers had access to financial resources (26.5\%), organizational support $(23.5 \%)$ and family support $(20.6 \%)$. Lower on the scale were the community $(7.4 \%)$ and caregiver support (8.8\%). (Figure 6)

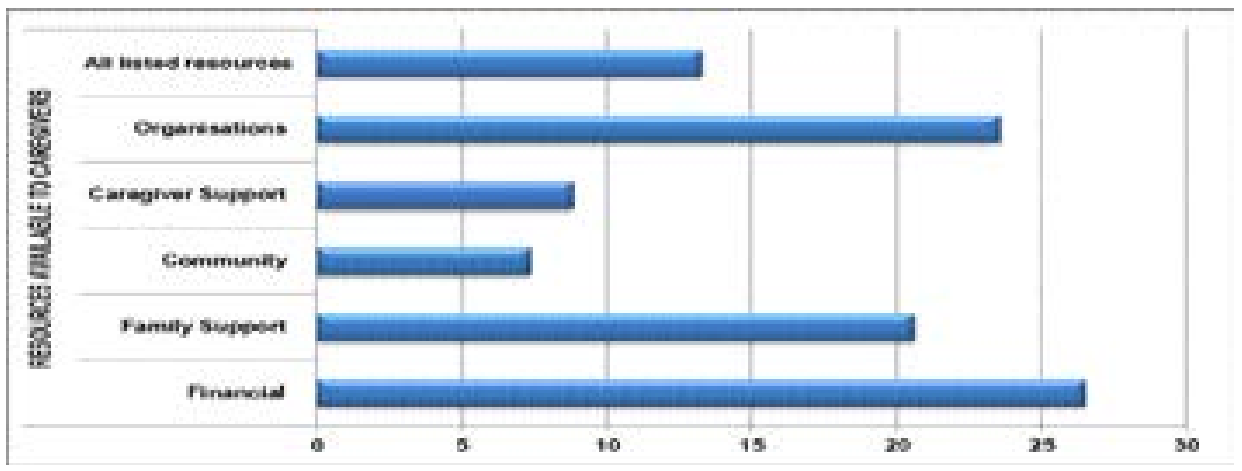

Figure 6: Resources available to Caregivers $(n=68)$

\section{Discussion}

The caregivers' initial reactions when discovering that the child had DS were mainly shock, sadness and anxiety. As indicated in other studies, ${ }^{9,16}$ the birth of a child that is not considered 'normal' evokes feelings of grief as the possibilities of typical development are eradicated, and there may be the sudden need for the caregiver to adapt to the novel situation ${ }^{8}$ which inevitably increases the intensity of the emotions experienced. The birth of a child with Down's syndrome and the loss of the ideal of a 'perfect' child has been well documented, ${ }^{9,17}$ and can be seen in this study to result in emotions that are not always positive.

When considering the etiology of Down's syndrome, the following were noted: caregivers showed that they understood that it was a medical condition relating to chro- 
mosomal abnormalities ${ }^{3}$ rather than attributing the syndrome to a fault of their own. It is possible that initial feelings of anxiety may in part be related to revealing this news to their family members and communities (Figure 5). The birth of a child with a disability, as indicated in other studies, ${ }^{4,20}$ adds stress to the family unit due to the demands that care-giving entails. The high level of mixed feelings around disclosure can be attributed to the stigmatization and prejudice, toward children who are not considered 'normal' by communities within an African context. ${ }^{519}$ This is further linked to the cultural opinions of the community attributing negative life events to bad spirits or inadequate cultural practices. ${ }^{5}$

Despite the immediate reactions, the caregivers' initial emotions toward the child rather than the situation have proven to be positive and unchanged by the compounding challenges. The caregivers showed feelings of love toward the child notwithstanding the diagnosis (Figure 2). Higher levels of confusion and anxiety were expected due to the multiple exacerbating factors, however, the elevated feelings of love toward the child was emphasized by majority of the caregivers. This is in keeping with other studies ${ }^{8,21,22}$ that show that the occurrence of a disability in the family results in the caregiver/s having to adapt their perceptions and adapt a sense of acceptance in order to problem solve and cope.

\section{Conclusion}

As limited research has been conducted on the perceptions of raising a child with Down's syndrome within an African perspective, this study provides an initial stance towards exploring the experience of raising a child with DS in this context, albeit with a limited sample. There is a need however to initiate more research towards caregivers and the impact on care-giving. Caregivers are often considered the hidden client and attention is often only directed towards the child in their care. Over time feelings of fear, guilt, frustration, uncertainty, anger, sadness and loss, chronic fatigue is seen. The psychosocial factors and interpersonal relationships surrounding child and caregiver are thus integral in informing interventions for caregivers. This simple descriptive study allowed for the subjective experience, perceptions and attitudes of a group of caregivers. These initial findings serve to raise further questions into the deeper meanings and experiences of caregivers through a more in-depth inquiry, such as one through a phenomenological lens. Perhaps through this exposition, one may assist practitioners in understanding the dynamics surrounding care-giving within this context that may contribute to holistic interventions.

\section{Conflict of interest}

None to declare.

\section{References}

1. Rajh YP. Factors contributing to stress in parents of children diagnosed with Attention Deficit/Hyperactivity Disorder. Masters in Education University of Kwazulu-Natal Edgewood Campus, 2005.

2. Sherman SL, Allen EG, Bean LH \& Freeman SB. Epidemiology of Down syndrome. Mental Retardation and Developmental Disabilities Research Reviews 2007; 13:221- 227.

3. Silverman W. Down syndrome: Cognitive phenotype,, Johns Hopkins University School of Medicine. 2007

4. Bazter C, Cummins RA \& Yiolitis L. Parental stress attributed to family members with and without disability: A longitudinal study. Journal of Intellectual \& Developmental Disability 2000; 25:105-118.

5. Lansdown G. Disabled children in South Africa: Progress in implementing the convention on the rights of the child. Rights for Disabled Children 2002:1-37.

6. Beresford B, Rabiee P \& Sloper P. Outcomes for parents with disabled children. Social Policy Research Unit 2007. [Online]. Available:http://www.york.ac.uk/inst/ spru/pubs/rworks/aug2007-03.pdf.

7. Buckley SJ \& Sacks B. An overview of the development of children with Down syndrome (5-11 years). . Down Syndrome Issues and Information 2001. [Online]. Available: http://www.down-syndrome.org/information/development/childhood/.

8. King LA, Scollon CK, Ramsey C \& WILLIAMS, T. 2000. Stories of life transition: Subjective well-being and ego development in parents of children with Down syndrome. Journal of Research in Personality., 34, 509-536.

9. Lam L \& MacKenzie AE. Coping with a child with Down syndrome: The experiences of mothers in Hong Kong. Qualitative Health Research 2002;12:223-237.

10. Lazarus RS \& Folkman S. Stress, appraisal, and coping., 11 West 42nd Street, New York, Springer Publishing Company, Inc. 1984.

11. Mosby. Mosby's Medical Dictionary. 8 ed. USA 2009: Elsevier Health Sciences.

12. Cifra-Bean, L., Brasington C, Maly K, Williams J, Hutchinson J, Albinali N \& Mattson J. 2012. Down Syn- 
drome. In: National Down Syndrome Congress. (ed.). Atlanta.: National Down Syndrome Congress (NDSC).

13. Ward C. History of Down's syndrome. 2002. Available:http:/ / www.intellectualdisability.info/changing-values/history-of-downs-syndrome [Accessed 25/01/2012]. 14. Lehohla P. Prevalence of disability in South Africa Census 2001. Pretoria: Statistics South Africa.

15. Naidoo H, Aldous C, Ramdhani H, Winship W, Henriques $\mathrm{N} \&$ Kormuth $\mathrm{E}$. Down syndrome in paediatric outpatient wards at Durban hospitals. South African Medical Journal 2011;101: 27-28.

16. Kearney KS \& Hyle AE. The Grief Cycle and educational change: The Kubler-Ross contribution. Planning and Changing 2003;34:32-57.

17. Lampret JC \& Christianson A. Reproductive choices made by South African mothers who have a child with Down syndrome. South African Medical Journal 2007:97.

18. Holland S. Educational psychology in practice: Theo- ry, research and practice in educational psychology. Journal of the Association for Educational Psychologists 1996;12:24-30. 19. Botha UA, Koen L \& Niehaus DJH. Perceptions of a South African schizophrenia population with regards to community attitudes towards their illness. Social Psychiatry and Psychiatric Epidemiology 2006;41:613-619.

20. Kaufman G \& Uhlenberg P. Effects of life course transitions on the quality of relationships between adult children and their parents. Journal of Marriage and the Family 1998;60:924-938.

21. Hodapp RM. Families of persons with Down syndrome: New perspectives, findings, and research and service needs. Mental Retardation and Developmental Disabilities. Research Reviews 2007;13:279-287.

22. Jakobsson E, Yleven R \& Moodley L. Problem solving and positive family functioning: Some reflections on the literature from a cross cultural point of view. South African Journal of Occupational Therapy 2007:14-17. 